Supporting Information for

\title{
A spectroscopic and electrochemical approach to the study of the interactions and photoinduced electron transfer between catechol and anatase nanoparticles in aqueous solution
}

\author{
Teresa Lana-Villarreal, Antonio Rodes, Juan M. Pérez, and Roberto Gómez* \\ Departament de Química Física i Institut Universitari d'Electroquímica, Universitat \\ d'Alacant, Apartat 99, E-03080, Alacant, Spain \\ E-mail: Roberto.Gomez@ua.es
}

Table of contents

1. Relative intensity of the adsorbate Raman bands as a function of the exciting wavelength

2. Effect of the exciting light intensity on the temporal evolution of the Raman spectra... 


\section{Relative intensity of the adsorbate Raman bands as a function of the exciting wavelength}

In this paper we show Resonance Raman spectra (RRS) for catechol adsorbed on anatase nanoporous thin films. Catechol forms a charge transfer complex upon adsorption on the $\mathrm{TiO}_{2}$ surface, which can be excited in the visible wavelength regime. To verify the Resonance Raman phenomenon, we have measured the intensity of the Raman bands both for the $\mathrm{TiO}_{2}$-Catechol complex and for an internal standard such as dissolved perchlorate whose Raman scattering is not enhanced. Table S1 shows the ratio between the different adsorbed catechol deconvoluted bands and that of the perchlorate band at $932 \mathrm{~cm}^{-1}$ for two different Raman excitation lines. The observed normalized intensity decreases for the $\mathrm{TiO}_{2^{-}}$ Catechol complex vibrational bands as the excitation wavelength is tuned from 514.5 to $632.8 \mathrm{~nm}$. This is an indication of the existence of resonance in agreement with the Ultraviolet-Visible absorption spectrum. Resonance enhancement is also found for some $\mathrm{TiO}_{2}$ vibrational modes, as previously reported by Hupp and coworkers. ${ }^{1,2}$

Table S1. Intensity for the $\mathrm{TiO}_{2}$-adsorbed catechol RRS bands normalized with respect to the $932 \mathrm{~cm}^{-1} \mathrm{ClO}_{4}^{-}$(aq) band intensity for 514.5 and $632.8 \mathrm{~nm}$ excitation lines. Raman spectra were obtained for a $\mathrm{TiO}_{2}$ slurry $\left(0.16 \mathrm{~g} \mathrm{ml}^{-1}\right)$ in presence of $14.5 \mathrm{mM}$ catechol in 0.1 $\mathrm{M} \mathrm{HClO}_{4}$.

\begin{tabular}{|c|c|c|}
\hline Frequency $/ \mathrm{cm}^{-1}$ & $\begin{array}{c}\text { Normalized intensity } \\
514.5 \mathrm{~nm}\end{array}$ & $\begin{array}{c}\text { Normalized intensity } \\
632.8 \mathrm{~nm}\end{array}$ \\
\hline 1261 & 8.03 & 1.78 \\
\hline 1329 & 14.9 & 1.62 \\
\hline 1483 & 15.9 & 2.42 \\
\hline 1584 & 22.2 & 4.65 \\
\hline
\end{tabular}

\footnotetext{
${ }^{1}$ Blackbourn, R.L.; Johnson, C.S.; Hupp, J.T. J. Am. Chem. Soc., 1991, 113, 1060.

${ }^{2}$ Hupp, J.T.; Williams, R.D. Acc. Chem. Res. 2001, 34, 808.
} 


\section{Effect of the exciting light intensity on the temporal evolution of the Raman spectra}

For very high light fluxes, catechol might be degraded to graphite (photopyrolysis) instead of polymerizing. In order to evaluate this possibility we have performed the same experiment using different light intensities (Figure S1). The observed behavior is similar in all cases: the bands characterizing adsorbed catechol are transformed into less defined features as fluorescence increases. The broad features appearing at 1350-1360 and 1590$1600 \mathrm{~cm}^{-1}$ are close to the frequencies of two typical bands for graphite. The Raman spectrum for graphite shows an intense band at $1582 \mathrm{~cm}^{-1}$, but when the carbon structure presents defects, another band appears at about $1330 \mathrm{~cm}^{-1}{ }^{3}$ In any case, the fact that the spectra obtained for different light intensities are virtually identical indicates that photopyrolysis (yielding graphite) is not the main process triggered by visible illumination. For an exciting laser light attenuated 100 times burning is unlikely.

\footnotetext{
${ }^{3}$ Nikiel, L.; Jagodzinski, P.N. Carbon, 1993, 31, 1313.
} 

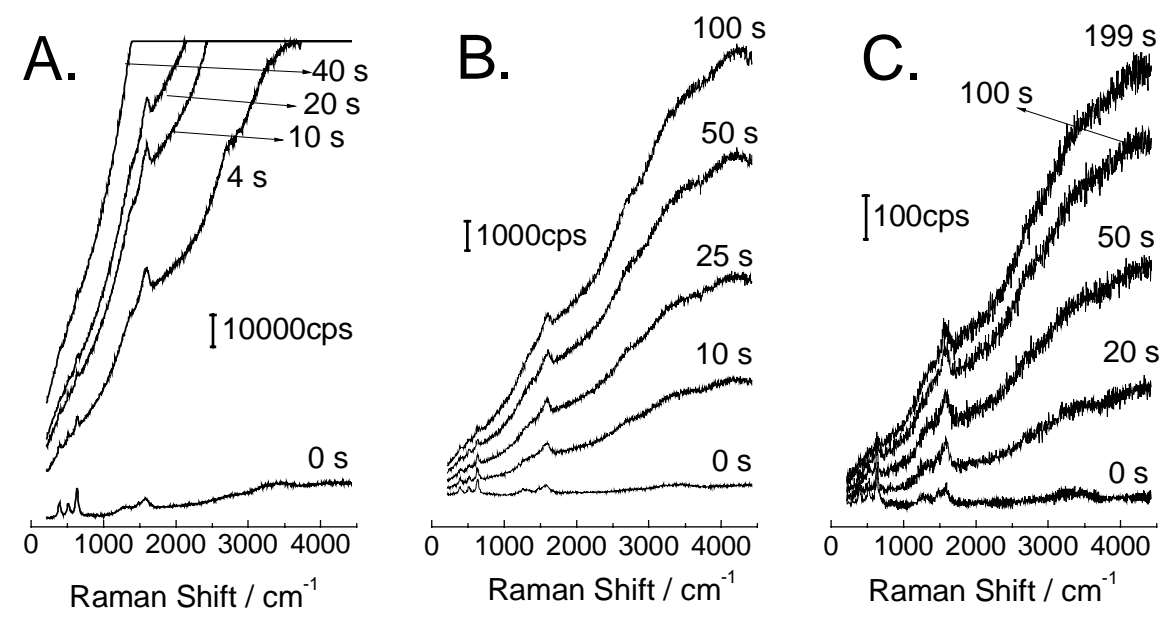

Figure S1. Time evolution of Resonance Raman Spectrum for an anatase thin film in contact with $14.5 \mathrm{mM}$ catechol in $0.1 \mathrm{M} \mathrm{HClO}_{4}$ using an $\mathrm{Ar}^{+}$laser as excitation line with different neutral density filters: A. without filter, B. absorbance $=1$, C. absorbance $=2$. Experimental parameters: $600 \mu \mathrm{m}$ pinhole; grating of $600 \mathrm{~g} / \mathrm{mm} ; 200 \mu \mathrm{m}$ slit. 